\title{
Regra numérica para a definição do vencedor de licitações: o caso dos arrendamentos portuários
}

\author{
Carlos Henrique Rocha* \\ Gladston Luiz da Silva* \\ Juliano Zaiden Benvindo ${ }^{* * *}$
}

\begin{abstract}
RESUMO - Devido à inexistência de uma regra desprovida de qualquer subjetividade para julgamento de propostas por ocasião de licitações públicas, é que muitos certames são impugnados. A literatura acadêmica não tem se ocupado em formular regras matemáticas objetivas e imparciais para a escolha da melhor proposta em licitações públicas. Este artigo procura preencher esta lacuna, propondo o uso de uma regra numérica para a definição do vencedor de processos licitatórios públicos ou privados. A regra proposta é de fácil aplicação e decorre dos conceitos de normalização e de uma interpolação entre os valores considerados para o cálculo do valor de referência. Pode-se dizer que a regra atenua a chamada maldição do vencedor. Uma simulação da regra é realizada com uma aplicação em um processo licitatório de arrendamento portuário; os dados são hipotéticos. Os arrendamentos portuários foram regulamentados a partir da Lei dos Portos e as licitações envolvem um número expressivo de critérios a serem avaliados. Considera-se que a regra, se adotada, tem potencial para aprimorar o ranqueamento e o julgamento das propostas feitas pelos concorrentes de licitações. Sempre que uma licitação envolver mais de um critério de julgamento, a regra proposta pode ser utilizada e independe se o critério de julgamento é quantitativo ou qualitativo.
\end{abstract}

Palavras-chave: Leilão. Normalização. Interpolação. Maldição do ganhador. Arrendamento portuário.

\section{INTRODUÇÃO}

Os leilões aparecem na história da humanidade desde longa data por volta do século V a. C. (MILGROM; WEBER, 1982), embora a teoria econômica do leilão tenha iniciado nos anos 60 (MILGROM, 2004). A literatura a respeito de leilões cresceu enormemente desde então, principalmente a internacional. Destaquem-se os seguintes autores, entre outros: Avinash Dixit, Charles Holt Jr., Dan Levin, John Kagel, Michael Rothkopf, Paul Milgrom, R. Preston McAfee, Richard Engelbrecht-Wiggans, Roberts Weber, William Vickrey.

Essa literatura tem produzido modelos econômicos de comportamento estratégico e de escolha do vencedor por ocasião do leilão, entre outras coisas. Os tipos básicos de leilões * Doutor em Economia pela Universidade de Liverpool. É professor adjunto da Universidade de Brasília. Endereço eletrônico: chrocha@unb.br.

** Doutor em Transportes pela Universidade de Brasília. É professor adjunto do Departamento de Estatística da Universidade de Brasília. Endereço eletrônico: gladstonsilva@ceftru.unb.br.

*** Doutor em Direito pela Universidade Humboldt de Berlim. É professor adjunto da Faculdade de Direito da Universidade de Brasília. Endereço eletrônico: juliano@unb.br. 
mencionados pela literatura especializada são: o inglês, de lances abertos e crescentes; o holandês, de lances decrescentes; o de lance fechado de primeiro preço; e o de lance fechado de segundo preço, também denominado de leilão de Vickrey. A principal diferença entre o leilão fechado de primeiro preço e o de segundo preço é que neste último caso, o valor de venda do objeto leiloado equivale ao segundo lance mais alto.

Os leilões e licitações públicos para a execução de obras, de arrendamentos de áreas portuárias, de áreas de telefonia móvel, de concessões rodoviárias, por exemplo, envolvem mais de um critério de julgamento ou atributo, como preço e patrimônio líquido mínimo exigido dos concorrentes. Os modelos existentes de leilão seguramente dão conta desses tipos de licitações públicas, assim: as empresas que possuíssem patrimônio líquido igual ou maior ao mínimo exigido estariam habilitadas a participar do processo formal de lance.

Este artigo apresenta uma regra numérica de decisão do vencedor de processos formais de lance, leilões e licitações, sejam públicos ou privados, tomando em conta simultaneamente todos os critérios de julgamento envolvidos.

Para este fim, este artigo é estruturado em cinco seções. A Seção 2 discorre sobre o princípio da licitação e sobre a necessidade de regras de julgamento objetivas e impessoais. A Seção 3 apresenta a regra proposta. A Seção 4 faz uma simulação de processo licitatório de arrendamento portuário, tal como normalmente conduzidos pelas autoridades portuárias sob a regulação da Agência Nacional de Transportes Aquaviários (ANTAQ); para uma melhor compreensão sobre os arrendamentos portuários no Brasil são sugeridos os textos de Rocha (2005) e de Rocha, Cavalcante e Gartner (2011). A última seção tem o objetivo de concluir o artigo.

\section{PRINCÍPIO DA LICITAÇÃO E NECESSIDADE DE REGRAS PRECISAS DE JULGAMENTO DE LICITAÇÕES}

Sabe-se que a licitação é um certame que os órgãos governamentais devem promover e no qual abrem disputa entre os interessados, travando determinadas relações de conteúdo patrimonial, para escolher a proposta mais vantajosa às conveniências públicas (MELLO, 2009).

O princípio norteador, portanto, que rege o processo licitatório é a competição, no intuito de ser escolhida a proposta que se mostre mais adequada ao poder público para a consecução de suas finalidades. Esse processo, que é complexo devido às distintas etapas que o compõe, tem, no julgamento da melhor proposta, um de seus momentos mais delicados e difíceis, na medida em que a proposta ganhadora deve ter sido submetida aos mais objetivos e transparentes critérios de avaliação, o que nem sempre é de fácil alcance.

A licitação, exigência que decorre diretamente do texto constitucional nas hipóteses 
especificadas, sobretudo em seus arts. 37, XXI, e 175 (concessões e permissões de serviço público), é regulada especialmente pela Lei Federal n. 8.666/93 e, no caso de serviço ou obra pública em regime de permissão ou concessão, pelas Leis Federais n. 8.987/95 e 9.074/95, que apontam algumas particularidades do processo licitatório nesse contexto sem afastar sua sujeição à Lei Federal n. 8.666/93.

Segundo o art. 37, XXI, da Constituição Federal de 1988:

ressalvados os casos especificados na legislação, as obras, serviços, compras e alienações serão contratados mediante processo de licitação pública que assegure igualdade de condições a todos os concorrentes, com cláusulas que estabeleçam obrigações de pagamento, mantidas as condições efetivas da proposta, nos termos da lei, o qual somente permitirá exigências indispensáveis de qualificação técnica e econômica à garantia do cumprimento das obrigações. (BRASIL, 1988).

Nos termos do art. 175 da Constituição Federal, “incumbe ao Poder Público, na forma da lei, diretamente ou sob regime de concessão ou permissão, sempre através de licitação, a prestação de serviços públicos".

Enfim, é esse o espectro normativo principal que estabelece as condições e regras gerais de como a licitação deve ser realizada e, particularmente, como as propostas devem ser submetidas a um critério de julgamento objetivo, transparente e imparcial que congregue os princípios regentes do direito administrativo, tais como a legalidade, a igualdade, a impessoalidade e a publicidade (MELLO, 2009).

Com efeito, o art. 45 da Lei n. 8.666/93 evidencia que:

o julgamento das propostas será objetivo, devendo a Comissão de Licitação ou o responsável pelo convite realizá-lo em conformidade com os tipos de licitação, os critérios previamente estabelecidos no ato convocatório e de acordo com os fatores exclusivamente nele referidos, de maneira a possibilitar sua aferição pelos licitantes e pelos órgãos de controle. (BRASIL, 1993).

A objetividade no critério de julgamento, desse modo, deve ser interpretada como uma condição imprescindível a um resultado adequado, fato que fica ainda mais evidenciado quando se tratar de licitação do tipo "menor preço", cujo critério de aferição não abre margens para maior discricionariedade na medida em que é pautado por elementos unicamente quantitativos.

Quando se trata de concessão de serviço público, nos termos do art. 15 da Lei n. 8.987/95, busca-se, do mesmo modo, alcançar um critério objetivo de julgamento das propostas. Para tanto, os elementos que devem ser levados em consideração são também quantita- 
tivos, a saber: o menor valor da tarifa do serviço público a ser prestado (inc. I) e a maior oferta, nos casos de pagamento ao poder concedente pela outorga de concessão (inc. II). A combinação de ambos os critérios também é possível, desde que "previamente estabelecida no edital de licitação, inclusive com regras e fórmulas precisas para avaliação econômico-financeira" (inc. III $\left.\mathrm{c} / \mathrm{c} \int 1^{\circ}\right)$.

Portanto, todo regramento usado para se obter a melhor proposta em hipóteses de licitações de "menor preço" e, mais especificamente, de concessões de serviço público, é trabalhado em termos quantitativos. É essa a premissa que deve, portanto, nortear a construção de uma fórmula que consiga definir o vencedor em licitações sem dar margem para eventual perda de objetividade e impessoalidade no julgamento e, ao mesmo tempo, esteja em consonância com as limitações legais acima.

Particularmente, este artigo utiliza como exemplo o caso de arrendamento portuário, que demanda um processo licitatório objetivo e imparcial de alta complexidade no julgamento. Aqui, como em diferentes outros contextos de julgamento da melhor proposta em licitações de objeto complexo e de grande vulto, a dificuldade em se definir a melhor proposta é evidente, caso não sejam previamente apresentadas regras e fórmulas precisas para a avaliação econômico-financeira. É importante, por isso, compreender como se caracteriza essa hipótese de licitação complexa e de grande vulto no âmbito do direito público.

A matéria referente a arrendamentos portuários é objeto da Lei n. 8.630/93, que institui o Regime Jurídico de Exploração dos Portos Organizados e das Instalações Portuárias, aplicando-se, de modo subsidiário, a legislação que rege as contratações e concessões de serviço público, conforme disposto nas Leis n. 8.666/93 e Lei n. 8.987/95. Do mesmo modo, o arrendamento aqui discutido refere-se à área cuja atividade nela exercida se caracteriza como serviço público (art. 21, XII, f, da Constituição Federal), portanto, regida pelas normas e princípios de direito público.

Ademais, embora não totalmente pacífico na doutrina brasileira (FERRAZ JÚNIOR, 1999), o contrato de arrendamento portuário é majoritariamente entendido (LOBO, 2000) como uma concessão de serviço público, concessão de uso de imóvel público ou concessão de obra pública. Isso pode ser visualizado pelo conteúdo das cláusulas essenciais determinadas pelo art. $4^{\circ}, \int 4^{\circ}$, da Lei n. 8.630/93, que têm típica feição de normas próprias do regime de concessão. Por isso, pode-se dizer que se trata de uma forma de concessão híbrida, sui generis, de serviço público, que pode trazer elementos da concessão de uso de bem público e também de obra pública em sua configuração.

Assim caracterizada a concessão, fica evidente que devem ser aplicadas as regras an- 
teriormente aludidas a respeito do processo licitatório, com especial ênfase no que determina a Lei n. 8.987/95. Por isso, dois aspectos devem ser levados em consideração: o menor valor da tarifa do serviço público prestado pela área arrendada (art. 15, I) e a maior oferta paga ao poder concedente para a outorga da área arrendada (art. 15, II). Esses dois critérios, como antes mencionado, podem ser combinados, desde que sejam estabelecidas regras e fórmulas precisas para o julgamento da proposta (art. 15, III c/c $\int 1^{\circ}$ ).

Com base na caracterização do arrendamento portuário como espécie de concessão de serviço público (com elementos de uso de bem público e de obra pública), mesmo que sui generis, a proposta deste artigo é apresentar exatamente uma fórmula que corresponda a esta precisão objetiva que determina a legislação aplicável. Para tanto, o intuito é apresentar uma regra que consiga congregar os seguintes elementos: menor valor da tarifa e maior oferta paga pela outorga. De modo a se alcançar um resultado que, enquanto objetivo e impessoal, se mostre também adequado o suficiente para a complexidade do processo licitatório nesse contexto.

\section{A REGRA}

A regra quantitativa sugerida para definir o vencedor de processo licitatório é dada por duas equações e pelos conceitos de normalização e interpolação. A primeira equação é como segue:

$$
V C A=\sum_{j=1}^{J} \varphi_{j} C_{j}
$$

onde $\sum_{j=1}^{n} \varphi_{j}=1$. Sendo que $V C A$ é o valor total do critério de julgamento do vencedor da licitação, $C_{j}$ é o critério de julgamento $j$ e $\varphi_{j}$ são pesos estabelecidos pela autoridade pública. Os critérios de julgamento mais relevantes devem assumir pesos relativamente maiores.

Na Tabela 1 são apresentados valores de referência para os critérios de julgamento. Este procedimento é uma espécie de normalização dos $C_{j}$ na Equação (1).

TABELA 1 - VALORES DE REFERÊNCIA PARA OS CRITÉRIOS DE JULGAMENTO

\begin{tabular}{l|c|cc|c}
\hline \multicolumn{1}{c|}{ Critério } & Menor valor & Maior valor & \multicolumn{1}{c}{ Valor intermediário } \\
\hline$C_{1}$ & & $x_{11}$ & $x_{12}$ & $x_{1 L}$ \\
$C_{2}$ & $x_{21}$ & $x_{22}$ & $x_{2 L}$ \\
$\ldots$ & $\cdots$ & $\cdots$ & $\cdots$ \\
$C_{n}$ & $x_{n 1}$ & $x_{n 2}$ & $x_{n L}$ \\
\hline
\end{tabular}

FONTE: Elaborado pelos autores.

O cálculo do valor $x_{j L}$ decorre da interpolação dos valores apresentados pelo L-ésimo licitante relativamente aos apresentados pelos critérios $j, V_{j \text {, min }}$ é o menor valor proposto por 
um licitante relativamente ao critério $j$, e $V_{j, \text { maxx }}$ é maior valor proposto por um licitante relativamente ao critério $j$.

Quando um licitante não apresentar o valor menor ou maior para determinado critério de julgamento, o valor intermediário $x_{j L}$ deve ser calculado conforme a seguinte expressão:

$$
x_{j}=\frac{V_{\text {máximo }}-\lambda \cdot V_{\text {minimo }}+V_{I}}{V_{\text {máximo }}-V_{\text {minimo }}}
$$

em que $\lambda=x_{i, \text { máx }}-x_{i, \text { min }}+1$.

Em resumo, a regra proposta representa um mecanismo de modelagem econômica para processos licitatórios quer públicos ou privados.

\section{SIMULAÇÃO}

Com a Lei de Modernização dos Portos, de 1993, os portos brasileiros passaram a adotar o modelo de administração portuária do tipo land lord, significando que os portos alugam, ou melhor, arredam suas áreas para a iniciativa privada explorar.

Em Lacerda (2005) e Marchetti e Pastoria (2006) encontram-se discussões pormenorizadas sobre a Lei dos Portos.

Os arrendamentos portuários, são conduzidos por meio de processos licitatórios. CEFTRU (2010) sugere os seguintes critérios de julgamento relevantes para o caso dos arrendamentos portuários. Pode-se dizer que os critérios funcionam como preços de reserva. São eles:

a) O valor do investimento mínimo para o empreendimento na área arrendada, em reais;

b) O preço máximo a ser cobrado do usuário do arrendamento pelo serviço prestado pelo arrendatário, em reais;

c) O preço mínimo a ser cobrado do usuário do arrendamento pelo serviço prestado pelo arrendatário, em reais;

d) Valor do aluguel a ser pago ao porto;

e) O valor referente ao down payment.

Ressalte-se, de antemão, que o conjunto de critérios acima busca congregar os dois 
elementos combinados determinados pelo art. 15 da Lei n. 8.987/95, na medida em que o segundo e o terceiro critérios referem-se à hipótese do menor valor da tarifa do serviço público a ser cobrado do usuário (inc. I) e os demais correspondem globalmente à maior oferta para a outorga da área arrendada (oferta que se traduz no valor global do aluguel, do investimento a ser feito na área arrendada e do valor do down payment). Tais critérios são apresentados objetivamente, de forma que se possa aferir, com precisão e impessoalidade, a melhor proposta, tal como exigido no art. $15, \sqrt{ } 1^{\circ}$, da Lei n. 8.987/95.

É importante registrar que o estabelecimento do preço mínimo visa evitar comportamentos oportunistas (ROCHA; CAVALCANTE; OLIVEIRA, 2011). Os preços de reserva (preços máximo e mínimo) atenuam o problema da maldição do ganhador em leilões (MILGROM, 2004). Não se aceita ofertas menores do que o valor piso para certo critério ou maiores do que o valor teto. Já o valor referente ao down payment é um prêmio pago pelo vencedor da licitação sem reembolso.

A par disso, o candidato a arrendatário $k$ deve fazer lances para os critérios de julgamento:
a) Preço a ser cobrado do usuário do arrendamento, $P$;
b) Valor do aluguel a ser pago ao porto, $V A$;
c) Valor mínimo do investimento na área do arrendamento, $I$;
d) Down payment, DP.

Os valores de referência para esses quatro critérios de julgamento são apresentados na Tabela 2 a seguir. A definição dos valores de referência $\chi_{i j}$ decorre da associação dos valores 1 ou 2, em acordo com o significado do respectivo critério. Por exemplo, caso o critério seja o preço $(P)$, ao concorrente que apresentar o menor preço deve ser atribuído o valor 2 , enquanto que para o concorrente que apresentar o maior preço deve ser atribuído o valor 1 . Por outro lado, caso o critério seja o investimento ( $I$ ) mínimo requerido pelo empreendimento, ao concorrente que apresentar o maior valor de investimento deve ser atribuído o valor 2, ao passo que para o concorrente que apresentar o menor valor de investimento deve ser atribuído o valor 1. 
TABELA 2 - VALORES DE REFERÊNCIA PARA OS CRITÉRIOS DE JULGAMENTO DOS ARRENDAMENTOS PORTUÁRIOS

FONTE: Elaborado pelos autores.

\begin{tabular}{l|r|r}
\hline \multicolumn{1}{c|}{ Critério } & Menor & Maior \\
\hline Preço (\$) & 2,0 & 1,0 \\
Arrendamento (\$) & 1,0 & 2,0 \\
Investimento (\$) & 1,0 & 2,0 \\
Down Payment $\$$ ) & 1,0 & 2,0 \\
\hline
\end{tabular}

Posto isso, a Equação (1) é reescrita para o candidato a arrendatário k (o sobrescrito $\mathrm{R}$ diz respeito aos valores de referência apresentados na Tabela 2):

$$
V C A_{k}=\varphi_{1} \cdot P^{R}+\varphi_{2} \cdot V A^{R}+\varphi_{3} \cdot I^{R}+\varphi_{4} \cdot D P^{R}
$$

Imagine-se, por simplicidade, que a autoridade portuária destina o mesmo peso a cada critério de julgamento relevante e que concorrem ao arrendamento três candidatos. Os valores ofertados pelos concorrentes para cada critério também estão apresentados a seguir.

TABELA 3 - VALORES OFERTADOS PELOS CONCORRENTES PARA CADA CRITÉRIO

\begin{tabular}{l|r|rr|rrr}
\hline \multirow{2}{*}{ Variável } & \multirow{2}{*}{ Parâmetros de referência } & \multirow{2}{*}{ Peso $\left(\varphi_{j}\right)$} & \multicolumn{3}{|c}{ Concorrente } \\
\cline { 4 - 7 } & $5,72 \leq \mathrm{P} \leq 7,57$ & 0,25 & & \multicolumn{1}{c}{ II } & \multicolumn{1}{c}{ III } \\
\hline$V A(\$)$ & $\geq 173.523,93$ & 0,25 & $173.523,93$ & $175.000,00$ & $178.000,00$ \\
$I(\$)$ & $\leq 3.000 .000,00$ & 0,25 & $3.000 .000,00$ & $4.000 .000,00$ & $5.000 .000,00$ \\
$D P$ & $\%$ do VA & 0,25 & $9 \%$ & $10 \%$ & $11 \%$ \\
& $(\$)$ & & $15.617,15$ & $17.500,00$ & $19.800,00$ \\
\hline
\end{tabular}

FONTE: Elaborado pelos autores.

Já os valores de referência, para cada critério de julgamento, ofertados pelos concorrentes são, segundo os valores de referência (Tabela 2) e a Equação (3):

TABELA 4 - VALORES DE REFERÊNCIA, PARA CADA CRITÉRIO DE JULGAMENTO, OFERTADOS PELOS CONCORRENTES

\begin{tabular}{|c|c|c|c|}
\hline & \multicolumn{3}{|c|}{ Concorrente } \\
\hline Critério & I & II & III \\
\hline$P(\$)$ & 1,50 & 2,00 & 1,00 \\
\hline$V A(\$)$ & 1,00 & 1,23 & 2,00 \\
\hline$I(\$)$ & 1,00 & 1,00 & 1,50 \\
\hline$D P(\$)$ & 1,00 & 1,45 & 2,00 \\
\hline$V C A$ (payoff) & 1,13 & 1,42 & 1,88 \\
\hline
\end{tabular}

FONTE: Elaborado pelos autores.

A título de exemplo, o licitante II obteve o valor de referência 2,00 para o critério preço porque ofereceu o menor preço. Foi atribuído ao licitante III o valor de referência 1,00 uma vez que ofertou o maior preço. O valor de referência para o licitante I de 1,50 foi obtido assim: 


$$
x_{j}=\frac{7,57-2 \cdot 5,72+6,65}{7,57-5,72}=1,50
$$

Conforme payoffs na tabela acima, o vencedor da licitação é o licitante III, com $V C A_{\text {III }}=1,88$. O licitante I obteve $V C A_{I}=1,13$ e o II, $V C A_{I I}=1,42$.

Finalmente, em caso de empate, deve ser dada preferência à proposta apresentada por empresa brasileira (art. 15, $\int 3^{\circ}$, da Lei n. 8.987/95) e, se prevalecer o empate, se procede ao sorteio (art. 45, \2 $2^{\circ}$, da Lei n. 8.666/93).

\subsection{CONSIDERAÇÕES ADICIONAIS SOBRE A REGRA PROPOSTA}

Cabe dizer que a regra proposta pode ser usada em qualquer certame, público ou privado, que estabeleça mais de um critério de julgamento, seja quantitativo ou qualitativo, para ranquear os concorrentes da licitação.

Usualmente, as licitações de obras públicas se valem de dois critérios relevantes: um critério quantitativo, menor preço, e outro qualitativo ou técnico. Diga-se que se pode facilmente apropriar valores de referência (1, 2 ou outro valor entre 1 e 2, exclusive os extremos, conforme Equação 2), como foi feito acima, para os critérios qualitativos e, então, aplicar a regra aqui sugerida.

Mais relevante, ainda, é o potencial da regra para fortalecer e oferecer credibilidade ao modus operandi do julgamento e do ranqueamento em licitações.

\section{CONCLUSÃO}

Este artigo propõe uma regra numérica objetiva para a determinação do vencedor de um processo licitatório, especialmente focando a hipótese de concessão de serviço público, aqui desenvolvida sob o estudo de caso do arrendamento portuário.

A regra apoia-se em dois fundamentos principais:
a) Normalização de valores;
b) Interpolação de valores.

Pode-se dizer que o mecanismo proposto atua no sentido de evitar a maldição do ganhador (MILGROM, 2004).

Sua aplicação vem de encontro à garantia do cumprimento do princípio da isonomia, 
expresso na Constituição Federal Brasileira, como a atuação do poder público de forma igualitária e sem distinção de pessoas, de forma objetiva e justa.

Por fim, deve ser dito que a regra pode facilmente ser também utilizada em processos licitatórios eletrônicos, sejam públicos ou privados. Para tanto, basta inserir parâmetros para os critérios selecionados e montar a equação de cômputo do payoff (resultado).

\section{REFERÊNCIAS}

CEFTRU. Relatório de pesquisa: aperfeiçoamento do processo de avaliação de viabilidade dos projetos de arrendamento portuário. Brasília, 2010.

FERRAZ JÚNIOR, T. S. Porto - arrendamento - cessão e prorrogação do contrato. Revista Trimestral de Direito Público, São Paulo, n. 26, abr./jun. 1999.

LACERDA, S. M. Investimentos nos portos brasileiros: oportunidades da concessão da infraestrutura portuária. BNDES Setorial, Rio de Janeiro, n. 22, 2005.

LOBO, C. A. S. Os terminais portuários privativos na lei n. 8.630/93. Revista de Direito Administrativo, Rio de Janeiro, n. 220, abr./jun. 2000.

MARCHETTI, D. S.; PASTORIA, A. Dimensionamento do potencial de investimentos para o setor portuário. BNDES Setorial, Rio de Janeiro, n. 24, p. 3-34, 2006.

MELLO, C. A. B. Curso de direito administrativo. São Paulo: Malheiros, 2009.

MILGROM, P. R. Putting auction theory to work. New York: Cambridge University Press, 2004.

MILGROM, P. R.; WEBER, R. J. A theory of auctions and competitive bidding. Econométrica, v. 50, n. 5, p. 1089-1122, 1992.

ROCHA, C. H. Uma proposta de precificação de arrendamentos de áreas portuárias. In: CONGRESSO USP DE CONTROLADORIA E CONTABILIDADE, 5., 2005, São Paulo. Anais... São Paulo: USP, 2005.

ROCHA, C. H.; CAVALCANTE, L. R.; GARTNER, I. R. Leasing policies for brazilian ports: a new perspective. Revista de Literatura dos Transportes, v. 5, n. 3, p. 4-15, 2011.

ROCHA, C. H.; CAVALCANTE, L. R.; OLIVEIRA, L. G. Estimating minimum and maximum fares of leased transport services. Applied Financial Economics, n. 1, p. 1-4, 2011. 